\title{
Creación del Ministerio de Ciencia, Tecnología, Conocimiento e Innovación
}

\author{
On the novel Chilean Ministry of Science, Technology, Knowledge and Innovation
}

\begin{abstract}
El 31 de mayo de 2018 el Congreso Nacional aprobó por unanimidad (130 votos y una abstención) en su último trámite legislativo en la Cámara de Diputados el proyecto que crea el Ministerio de Ciencia, Tecnología, Conocimiento e Innovación (MinCTC\&I). En los medios de comunicación se ha resaltado que esta aprobación haya tenido lugar con el apoyo de dos gobiernos de distinto signo y con la anuencia transversal de todas las tendencias politicas representadas en el Congreso Nacional. El Presidente de la República dispone de un año de plazo luego de esta aprobación del Poder Legislativo, para dictar el decreto correspondiente con la fecha de inicio del funcionamiento de este $24^{\circ}$ ministerio del Gobierno de Chile.
\end{abstract}

Luego de más de cinco años de peticiones y promesas, la creación de este ministerio hizo realidad una sentida aspiración de la comunidad cientifica de nuestro país, que espera que esta nueva institucionalidad permita asegurar el impacto de la ciencia nacional en la generación de conocimiento tan necesario para el desarrollo de nuestra sociedad.

El proyecto crea una nueva institucionalidad para la ciencia, tecnología, conocimiento e innovación, constituyéndose los siguientes organismos operativos: a) un ministerio; b) una Agencia de Investigación y Desarrollo encargada de las funciones que actualmente tiene la Comisión Nacional de Ciencia y Tecnología (CONICYT); c) un Consejo Nacional de Ciencia y Tecnología, integrada por 15 miembros que se encargará de elaborar una estrategia nacional de ciencia, tecnología e innovación para el desarrollo; d) Cinco Secretarías Regionales Ministeriales; e) un Consejo Asesor Ministerial de 8 miembros con reconocido prestigio en ciencia, tecnología e innovación y f) un Comité de Ministros que incluye 4 ministerios: CTC\&I, Hacienda, Economía, Fomento y Turismo y Educación.

El ministerio de CTC\&I estará encargado de diseñar, formular, coordinar, implementar y evaluar las políticas, planes y programas destinados a fomentar y fortalecer las cuatro áreas que le dan su nombre y que están íntimamente relacionadas con la investigación científica y tecnológica nacional.

Lamentablemente nuestro país ha realizado una exigua inversión en el desarrollo de ciencia y tecnología. Actualmente Chile invierte en este importante rubro solo un 0,38\% de su producto interno bruto (PIB), lo cual lo ubica en el último lugar de los países de la OCDE (Organización para la Cooperación y Desarrollo Económico) al comparar este rubro, en que los países que ocupan los primeros lugares en esta inversión como Corea de Sur e Israel lo hacen con un 4,5\% de sus respectivos PIBs. La ley aprobada no compromete un mayor gasto fiscal para los fines que desea promover. De aqui nace una inquietud visceral de la comunidad cientifica que ha empezado a eclipsar el razonable júbilo que debió experimentar con la aprobación de esta ley. Si la creación de este ministerio no va aparejada de la voluntad política de aumentar progresivamente el porcentaje del PIB destinado al presupuesto de este ministerio, la loable proposición de esta ley en pro de fomentar la ciencia, tecnología e innovación quedará reducida a una nueva modalidad burocrática de administrar los insuficientes fondos dedicados a estos propósitos, frustrando una vez más los anhelos de quienes cifraron sus esperanzas en crear una sociedad del conocimiento como una poderosa palanca de desarrollo de nuestro país. 
Es indispensable entonces que la participación ciudadana cree espacios e instancias de decisión para la discusión de un financiamiento apropiado y suficiente para el desarrollo e instauración no solo de la compleja malla o matriz de los organismos que formarán parte de este nuevo ministerio, sino para lograr el adecuado fomento e implementación de políticas públicas que permitan el desarrollo de la ciencia, tecnología e innovación tan necesarios para un real desarrollo de una sociedad del conocimiento en nuestro país.

La sombría perspectiva planteada por esta falta de aporte fiscal para mejorar el financiamiento de las iniciativas que esta ley pretende promover se ha visto iluminada por el interés del actual ministro de hacienda, D. Felipe Larraín por la ciencia y tecnología que se ha expresado en la reciente publicación de un texto en conjunto con el profesor de la Pontificia Universidad Católica de Chile José Miguel Aguilera y ex presidente de CONICYT, titulado: "Laboratorios Naturales para Chile. Ciencia e Innovación con ventaja". En la introducción de este libro el profesor Jeffrey Sachs economista de la Universidad de Harvard plantea que a menudo los países se descuidan en movilizar la Ciencia y la Tecnología para resolver los desafios críticos de la sociedad y estimular el crecimiento económico a largo plazo. En muchos países en desarrollo la inversión en investigación $y$ desarrollo es insuficiente para abordar problemas críticos de salud, gestión ambiental, protección a la biodiversidad, desastres naturales entre otros que imponen enormes barreras al desarrollo económico. Este libro propone utilizar las ventajas comparativas de Chile como un "laboratorio natural" para abordar problemas clave a nivel planetario atrayendo investigación multidisciplinaria de todo el mundo. El desarrollo de la astronomía en el Norte Grande, las exploraciones antárticas y la resiliencia frente a desastres de origen natural son algunos de los ejemplos abordados en este libro por expertos nacionales en estos temas. Si bien el libro se centra en los eventuales aportes de estos "laboratorios naturales" es esperable que el abordaje de los problemas económicos a través de un mayor desarrollo de la ciencia y la tecnología se extienda también a otras importantes áreas generadoras de conocimiento.

La profesora de la Universidad de Chile Dra. Cecilia Hidalgo, premio nacional de Ciencias Naturales 2006 ha considerado como "notable e inédito que en este libro el ministro Larraín se refiera a la ciencia y a la tecnología en Chile como actores relevantes para promover la diversificación de la matriz productiva y exportadora del país y es destacable que coincida con la generación del conocimiento en el centro de nuestro modelo de desarrollo".

Esta visión del ministro Larraín proyecta una luz de esperanza en que el decreto gubernamental que creará el Ministerio de Ciencia, Tecnología, Conocimiento e Innovación podrá corregir algunas de las deficiencias que se han detectado en el proyecto de ley recientemente aprobado.

Un aspecto que ha inquietado a los organismos universitarios, cientificos e inventores interesados en el patentamiento de sus iniciativas ha sido uno que se refiere a la propiedad industrial y que establece que si el investigador o la institución que recibió financiamiento estatal logra comercializar en cualquier forma su derecho de propiedad industrial, deberá restituir el 100\% de los fondos recibidos y una suma adicional equivalente al $5 \%$ de los ingresos obtenidos de la comercialización del derecho de propiedad industrial. Se considera que esta obligación constituiría una restricción para el patentamiento y la transferencia tecnológica y que transformaría al Estado en un inversionista que exige una retribución, más que en un incentivador de políticas de innovación que es el espíritu de la ley de creación de este ministerio. En este sentido sería importante establecer una normativa complementaria que motive efectivamente el patentamiento y la transferencia tecnológica.

Otro tema que debe tenerse presente en el accionar del ministerio de CTC\&I es cómo se incentivarán las actividades inherentes en las regiones. Inicialmente se contemplan cinco Secretarias Regionales Ministeriales (SEREMIs) en macrozonas que al cabo de diez años darán origen a una SEREMI en cada una de las 16 regiones que tiene nuestro país. Los escasos investigadores que existen actualmente en las regiones se sienten actualmente discriminados por la excesiva centralización de las actividades de ciencia, tecnología e innovación en la Región Metropolitana que habitualmente se adjudica la mayor parte del ya escuálido presupuesto nacional para estos fines. 
Considerando lo expuesto es crucial para resolver las dudas planteadas ante la creación de este nuevo ministerio que el decreto gubernamental que lo ponga en funcionamiento logre subsanar las falencias detectadas en el proyecto aprobado y que el presupuesto para sustentar su operatividad sea ajustado progresivamente cubriendo cabalmente las necesidades que se pretenden atender con esta promisoria iniciativa.

Dr. Manuel Oyarzún G. Profesor titular, Facultad de Medicina, Universidad de Chile Miembro Comité Científico, Sociedad Chilena de Enfermedades Respiratorias

Email:moyarzun@med.uchile.cl

\section{Bibliografía}

1.- DE LA FUENTE G, HAMUY M. Proyecto de ley que crea el Ministerio de Ciencia, Tecnología e Innovación. Enero 2018. Disponible en: https://www.camara.cl/pdf.aspx?prmID=122685\&prmTIPO=DOCUMENTOCOMISION. (Fecha de la consulta: 3 de julio de 2018). 